Esta obra está bajo una Licencia Creative Commons Atribución - No Comercial - Sin Derivar 4.0 Internaciona

(c) $(1) \Theta(\Theta$

Política y moralidades en torno a la implementación del PROGRESAR en la ciudad de Olavarría

Matías Rafael Pizarro

Question, Vol. 1, N. 62, e164, abril-junio 2019

ISSN 1669-6581 | https://doi.org/10.24215/16696581e164

http://perio.unlp.edu.ar/ojs/index.php/question

FPyCS | Universidad Nacional de La Plata

La Plata | Buenos Aires | Argentina

\title{
Política y moralidades en torno a la implementación del PROGRESAR en la ciudad de Olavarría
}

Politics and morals around the implementation of PROGRESAR in the city of Olavarría

Matías Rafael Pizarro rafapizarro18@gmail.com

Facultad de Ciencias Sociales;

Universidad Nacional del Centro de la Provincia de Buenos Aires (Argentina)

\section{Resumen}

El artículo aborda etnográficamente la implementación de PROGRESAR en una ciudad de la Provincia de Buenos Aires en el período que recorre desde 2014 a 2017 (1). Se focaliza en los aspectos políticos y morales que emergen alrededor de su ejecución y que se cristalizan en 
tramas más amplias que involucran actores, instituciones y prácticas. De esta manera, se busca identificar las formas en que diversas valoraciones e ideas se ponen en juego y se articulan en torno a moralidades y normatividades que desbordan los aspectos legalesformales estipulados en el Decreto 84/2014 que dio creación a esta política, poniendo de relieve disputas, reciprocidades, lealtades, sospechas e impugnaciones. La observación analítica se centra en los esquemas de significación trazados por jóvenes destinatarios del programa y militantes estudiantiles dentro del nivel universitario. Como parte del trabajo de campo se realizó observación participante, entrevistas personales y sistematización de fuentes secundarias.

Palabras clave: Progresar; moralidad; militantes; jóvenes.

\section{Abstract}

The article addresses ethnographically the implementation of PROGRESAR in a city of the Province of Buenos Aires in the period that runs from 2014 to 2017. It focuses on the political and moral aspects that emerge around its execution and that crystallize into plots broader that involve actors, institutions and practices. In this way, it seeks to identify the ways in which various valuations and ideas are put into play and are articulated around moralities and regulations that go beyond the legal - formal aspects stipulated in the decree 84/2014 that gave rise to this policy, putting highlight disputes, reciprocities, loyalties, suspicions and challenges. The analytical observation focuses on the meaning schemes drawn by young people who are recipients of the program and student militants within the university level. As part of the field work, participant observation, personal interviews and systematization of secondary sources were carried out.

Keywords: Progresar; morals; militants; youth.

Durante el período que va desde 2003 al 2015, desde el sector público se implementaron diversas políticas de Transferencias Condicionadas de Ingresos (TCl), destinadas a sectores sociales vulnerables en diferentes escalas estatales. Entre éstas, se ubica el programa nacional denominado PROGRESAR (Programa de Respaldo a Estudiantes de Argentina), dirigido a jóvenes entre dieciocho (18) y veinticuatro (24) años de edad y orientado a la finalización de sus estudios en cualquiera de sus niveles. Estos programas fueron identificados, 
por diferentes sectores, con la etapa de gobiernos kirchneristas y presentados, oficialmente, dentro de un paradigma de "recuperación de derechos". El cambio de gobierno suscitado a partir de 2015 implicó una reorientación en las políticas públicas en el marco de las cuales algunos aspectos asociados a la implementación de este programa se vieron afectados.

En el presente trabajo se aborda la implementación de PROGRESAR en la ciudad de Olavarría entre 2014 y 2017, atendiendo a diversos sentidos que emergen durante este proceso y que se enlazan en tramas de significaciones más amplias construidas alrededor de este tipo de política, tomando como marco las relaciones sociales y políticas creadas a través de su ejecución. La observación analítica se centra en los esquemas de significación trazados por jóvenes destinatarios del programa y militantes estudiantiles dentro del nivel universitario, que desbordan la normativa oficial estipulada como así también la dimensión meramente económica presente en estas transacciones. Estos sentidos en ocasiones son construidos en torno a una retórica del derecho, en otras problematizados por los actores a partir de la idea de regalo y para otros casos se observa la incidencia de valores asociados a la militancia política. De esta manera, damos cuenta del carácter complejo que adquiere este proceso en el cual convergen múltiples valores, reciprocidades, lealtades, disputas, actores y prácticas. Este panorama prefigura heterogeneidades e imbricaciones que caracterizan a las relaciones establecidas durante la implementación de esta política y que se revelan a la luz de las controversias morales que la misma suscita. Se toman en cuenta los contextos políticos que delimitan etapas diferentes del proceso, sobre las cuales algunos elementos señalados se ponen en juego en el marco de una reorientación política que incide en el mismo.

\section{El decreto y sus intersticios}

El 22 de enero de 2014, la entonces presidenta de la Nación Cristina Fernández de Kirchner, anunció el lanzamiento del Programa de Respaldo a Estudiantes de Argentina -de aquí en adelante Progresar-, destinado a jóvenes entre 18 y 24 años para el inicio y/o finalización de sus estudios en cualquiera de los niveles, incluyendo capacitaciones y formación en oficios. El día posterior, el anuncio se oficializó a través del Decreto 84/2014 (2) que estableció las modalidades de gestión, implementación y requisitos de acceso al programa. Según los requisitos instituidos inicialmente, accedían al programa los jóvenes que no trabajaran, trabajaran informalmente o tuvieran un salario menor al salario mínimo vital y móvil; siendo las mismas condiciones aplicables a su grupo familiar. Posteriormente, estas fueron modificándose a lo largo del proceso de aplicación (3). 
Como aspecto distintivo del decreto, a tono con un conjunto de políticas de transferencias condicionadas -como por ejemplo la Asignación Universal por Hijo (AUH)-, se establecieron las condicionalidades estipuladas para garantizar la continuidad de los y las beneficiarias en el programa, que radicaron principalmente en la acreditación de escolaridad (a través de diferentes formularios) y un control anual de salud. Sin embargo, no se formalizó ninguna regulación en torno al dinero de la transacción; no se explicitaron modalidades de reclamo ante alguna irregularidad que llegara a surgir; y tampoco se abarcaron modalidades de gestión que luego se fueron configurando en el proceso de implementación. Esta situación nos abre una puerta para la comprensión de algunas dimensiones dinámicas que se activan en el marco de la implementación de este tipo de políticas, sobre las cuales identificamos dos que están en permanente solapamiento e interrelación: política y moral.

En lo que respecta a la primera, se identifican una serie de actores que fueron claves para la implementación. El decreto estableció que el organismo encargado de la gestión y otorgamiento del estipendio mensual estipulado era la Administración Nacional de la Seguridad Social (ANSES), pero en los eventuales intersticios normativos y políticos, otros actores comenzaron a visualizarse y a ganar lugar en la gestión del Progresar. En este sentido, en Olavarría las organizaciones políticas constituyeron un importante núcleo de divulgación del programa. Grupos de militantes de diferentes organizaciones, se dirigían a diversos barrios de la ciudad "a militar el Progresar". Estas acciones, desde el esquema de significaciones militante, estaban guiadas por las palabras enunciadas por Cristina Fernández de Kirchner, en las cuales hacía alusión a que había que ir a buscar a los jóvenes a los cuales el programa se dirigía, diciendo ante un público repleto de militantes y representantes de diferentes organizaciones sociales, sindicales, políticas: "tenemos que ir al territorio a trabajar, junto a los que más lo necesitan, junto a los que más demandan la presencia de sus semejantes” (4).

En poco tiempo, además del sentido informativo que orientaba estas actividades, los militantes también comenzaron a realizar inscripciones al programa. Un caso particular alude al Centro de Estudiantes (CE) de la Facultad de Ciencias Sociales de Olavarría (FACSO), en ese momento bajo conducción de la Unión de Estudiantes de Sociales (UNESO) -una organización peronista kirchnerista- que a partir de finales de febrero de 2014 se constituyó en un Centro de información del programa, lugar en el cual se podían encontrar los formularios para realizar inscripciones además de diferentes folletos informativos, junto a la presencia de los militantes que acompañaban y asesoraban a los jóvenes con el trámite. Esto tuvo que ver con un acuerdo que a principios de ese mes habían establecido la ANSES local y las diferentes organizaciones. Luego de ingresado los trámites, que eran completados en la misma fotocopiadora del Centro, 
desde la Secretaría de Bienestar del CE se llevaba semanalmente a la oficina local de la dependencia estatal una carpeta con las planillas de las inscripciones realizadas.

De lo descripto anteriormente, se desprenden algunas ideas que pueden echar luz en el análisis desde el cual se exploran estas dinámicas situadas sobre los intersticios del programa. Más allá del esfuerzo militante dirigido a captar la mayor cantidad posible de destinatarios, la modalidad de implementación estableció lógicas de acumulación de legitimidad y reconocimiento. En lo que respecta al caso de la FACSO, la agrupación que entonces conducía el CE, se hizo de una herramienta política que le permitió establecer nuevos lazos políticos y construir cierta legitimidad en el conjunto de los estudiantes. En un contexto político donde la Franja Morada ya no tenía representación ni participación activa en el $C E$, y la única agrupación opositora (izquierda trotskista) ya se estaba desmembrando, además de la sintonía con el contexto nacional, la UNESO se mostraba como la única agrupación junto a los estudiantes. Y el Progresar comprendió un importante emblema discursivo dentro de esta dinámica. Reuniones periódicas junto a los estudiantes destinatarios, encuentros programados para realizar el trámite de inscripción online, visitas en horarios de cursadas, acuerdos institucionales, fueron materializando una narrativa militante del programa sobre la base de una idea articuladora que atravesó las acciones y discursividades de los militantes estudiantiles: la de derecho.

A través de este señalamiento, nos introducimos en la dinámica moral sobre la que se inscribe el Progresar. Y para poder deslizar una aproximación analítica sobre esta dimensión, resulta revelador el concepto de sensibilidad legal acuñado por Geertz (1994). En su trabajo, el autor aborda la construcción de sentidos vernáculos de justicia que articulan ideas singulares de hecho y ley, en el marco de procesos judiciales situados en contextos culturales específicos. Señala que el fenómeno jurídico no implica una prestidigitación, un proceso cerrado, el cual no se limita al conjunto de normas, reglas, principios, valores o cualquier otra cosa a partir del que puedan plantearse respuestas legales a una serie de acontecimientos destilados. El antropólogo pone énfasis en la cuestión de la representación, y propone denominar estos sentidos de justicia como sensibilidades legales, las cuales no son sino parte de una manera determinada de imaginar lo real. Inspirados en esta idea, y salvando las distancias analíticas entre ambas investigaciones, se busca profundizar sobre los aspectos del programa que desbordan los límites de lo meramente formal-legal y dan cuenta de las tramas morales que lo atraviesan en su cotidianeidad.

En este sentido, la noción de derecho aparece como articuladora de los sentidos elaborados por los militantes estudiantiles de UNESO en relación a los hechos, principios y procedimientos vinculados a la implementación del programa, los cuales son construidos sobre el valor de 
justicia. Para lograr mayor claridad sobre esta última idea, un ejemplo recogido a instancias del desarrollo del trabajo de campo (2014-2017) resulta revelador de esta afirmación. Una vez puesta en marcha la modalidad de implementación del programa a nivel local, varios jóvenes habitantes de barrios próximos a donde se encuentra ubicado el campus universitario comenzaron a acercarse al CE para iniciar el trámite de inscripción. Un rasgo particular de esta situación tenía que ver con la fecha del año en el que esto sucedía: mediados de febrero, momento en que aún las clases para los niveles escolares, como así también las cursadas en el nivel universitario, no habían comenzado. De esta manera, era frecuente que los primeros jóvenes que se acercaran al lugar fueran estudiantes de nivel secundario. Este fue el caso de un joven que aún transitaba su escolaridad secundaria, quien luego de unos días de haber iniciado el trámite en el CE -a través de la modalidad online en el sitio de la ANSES- regresó para comentar que las autoridades del establecimiento escolar se habían negado a firmar uno de los formularios requeridos para la inscripción, planilla que debía contar con el aval del directivo correspondiente a la institución en la cual el joven realizara sus estudios. La respuesta de los militantes estudiantiles aquella media mañana acalorada de febrero fue enfática: "no pueden hacer eso, es un derecho". Paralelo a sus gestos y expresiones de disgusto, le recomendaron al joven que volviera a dirigirse al establecimiento señalándole a las autoridades correspondientes que tenían el compromiso de firmar dicho formulario porque "esto no es una beca, es un derecho y no lo pueden negar".

Esta última situación narrada, también puede conectarse con las diferentes gramáticas de enunciación que modelaron las discursividades sobre el Progresar y que se cruzaron en la disputa de sentidos. Retomando el ejemplo etnográfico recién señalado, el rechazo por parte de las instituciones a firmar el formulario aduciendo que no podían firmar una planilla de ese tipo si no contaban con la seguridad de que una vez iniciado el ciclo escolar el joven continuara con sus estudios de manera regular, era una postura habitual. Algo similar sucedía en el nivel universitario cuando se daba inicio al curso introductorio, que no se enmarca institucionalmente dentro del calendario de cursadas. En este sentido, desde la oficina de alumnos afirmaban que no estaban en condiciones de firmar el formulario de quienes se encontraban cursando dicho curso, ya que aún no eran estudiantes regularizados. La contraparte discursiva desde el conjunto de los militantes volvía a enmarcarse en la noción de derecho.

Más allá de los vericuetos burocráticos que también formaban parte de la implementación del programa, esta especie de "ilegalidad" vislumbrada desde la condición de regularidad de un estudiante encuentra asidero en un conjunto más amplio de significaciones construidas sobre las políticas de este tipo, en general, y sobre los destinatarios, en particular. Tramas tejidas en medio de sospechas, impugnaciones simbólicas y juicios morales. Recurrentes y sistemáticas 
solían ser las exigencias de una mayor rigurosidad a la hora de "controlar" cómo se gestionaba el programa, categoría nativa a través de la cual se expresaba quien debía o no ser beneficiaria/o del programa y cuáles eran las exigencias (morales) a cumplir para acreditar esta condición, excediendo el decreto y los fundamentos oficiales asociados a la creación del mismo. Un núcleo discursivo, apoyado mediáticamente, hacía alusión a ciertas condiciones materiales de existencia de los y las jóvenes destinatarias, caracterizados a modo de impugnación bajo la categoría "ni-ni" (5). A su vez, este discurso se enlazaba con otros que ponían el ojo en el dinero entregado a modo de estipendio mensual por el Estado. De esa manera, este frente discursivo se valió de dos elementos centrales que puso a prueba y a juicio: los jóvenes destinatarios y el dinero transferido. De una retórica del derecho se abrió paso a otra que tomó como núcleo significacional -con diferentes matices- la noción de regalo, vinculada a condicionalidades implícitas dentro de ese intercambio. En diferentes oportunidades, la idea del "regalo" o el dinero que "viene de arriba" fue expresada en boca de los jóvenes destinatarios quienes emanaban estas concepciones vinculadas a esquemas y juicios morales donde se ponían en tensión emociones, sentimientos y relaciones familiares. En una entrevista realizada durante 2014, una joven beneficiaria del programa me comentó que a diferencia de lo que algunas personas decían, no consideraba al Progresar como un regalo y esto la enfrentaba con su madre:

[...] No es que te están, como dicen muchos, que es un regalo. No te están regalando plata. Te están incentivando y ayudando para que vos el día de mañana tengas un título, una carrera una salida laboral. Mi mamá siempre me dice, porque yo voy a la peluquería y estoy toda la tarde ahí y hablo con todas las clientas que ya me conocen de chiquitita, y me dice que ni se me ocurra decir que cobro el Progresar, porque "qué vergüenza". Mi mamá tiene todas esas ideas de diva en la cabeza. Y yo si re orgullosa, "sí, yo cobro el Progresar". Qué se yo, para mí es como te digo, para mi es re lindo, para mi es una ayuda, es un... hasta un orgullo, que se yo. Me están ayudando a estudiar, y sí... si... qué problema hay. "Ay si nena, yo estoy todo el día acá trabajando van a pensar que me gasto la plata en botas" [...] "Como vas a aceptar ayuda de otros". Por sus aires de diva que tiene. Pero... es una discusión eterna que vamos a tener. Ella siempre dice "vos agarrá, agarrá todo que ella le regala a todos". Es muy feo lo que voy a decir, "ella le regala a todos los negros, agarrá una vez que le dan algo bueno a nosotros vos agarrá nena, agarrá (Comunicación personal, beneficiaria $A$, septiembre de 2014).

Los aportes de Wilkis $(2013,2015)$ y Matta (2013) nos ayudan a pensar de sobremanera esta última relación señalada, enfatizando en los diferentes regímenes de disputa moral que intervienen en la implementación de una política de transferencia condicionada. El extenso 
fragmento citado aparece esclarecedor sobre lo que Wilkis (2013) denomina las sospechas del dinero. En un trabajo más reciente, el autor sostiene que el dinero es "un poder que no se puede controlar completamente y eso genera sospechas" (Wilkis, 2015: 564). En un análisis sobre el dinero en el "mundo popular", el investigador señala que la monetización de la política social ha desplegado un espacio monetario en el cual las clases populares se exponen a ser juzgadas moralmente. En ese sentido, expresa que "el derecho a tener o no una protección social monetaria por parte de los más necesitados pasa a convertirse en tema de discusión y quienes opinan lo hacen con la potestad de juzgar los usos del dinero. Los juzgadores se convierten así en emprendedores morales (Becker, 2009) a través del dinero público, y éste se vuelve dinero sospechado" (2015: 565). Al dinero proveniente de las políticas sociales, Wilkis (2013) lo denomina dinero donado. Para el caso recuperado, los "negros" son juzgados bajo la retórica del regalo y a través de los usos del dinero, juicio que se torna latente sobre su entorno teniendo en cuenta que su hija es beneficiaria de una política social, por lo cual la mujer también se expone a la sospecha del dinero ("van a pensar que me lo gasto en botas") y esto le genera un sentimiento de vergüenza. Mientras que de su parte, la destinataria expresa un sentimiento de orgullo, y en ese sentido resulta también reveladora la idea de que el dinero como una pieza- "conecta a las personas a través de esperanzas, afectos, deseos, respeto, orgullo, odios y conflictos" (Wilkis, 2015: 567) (6).

Por otra parte, ser parte del intercambio social en el cual se enmarca el Progresar implica someterse a una serie de condiciones suscriptas a esquemas de valoraciones morales. Sobre éstos, se ponen a prueba las virtudes individuales de los destinatarios a través de una serie de obligaciones, de las cuales su cumplimiento deriva en el reconocimiento de los mismos como destinatarios legítimos. Esta idea nos conecta con el aporte clásico sobre la teoría del don (Mauss, 1979) acerca de las tres obligaciones constituyentes del intercambio social: dar, recibir y devolver. En el contexto de implementación de este tipo de políticas, la obligación referida a la devolución se ha convertido en el eje articulador de una serie de juicios y valoraciones enfocadas sobre los receptores de las mismas. En la misma entrevista, la joven afirmaba:

\footnotetext{
Porque en mi familia siempre se habló de una asignación por hijo pero que haya que devolver algo. [...] Cobras una asignación pero anda a barrer una plaza, anda a pintar una escuela. [...] Mi familia quiere cobrar un plan a cambio de ir a pintar una escuela, una plaza... Y yo hoy lo estoy cobrando por ir a estudiar (Comunicación personal, beneficiaria A, septiembre de 2014).
}

Como adelantábamos antes, un conjunto de normativas no fueron contempladas en el decreto oficial 84/2014 y esos intersticios legales son llenados por distintas valoraciones que se apoyan 
en sensibilidades legales singulares. Estas valoraciones se enlazan a través de un conjunto de normatividades morales que exigen que los destinatarios se sometan a una serie de obligaciones con el objetivo de acreditar moralmente su legitimidad en tanto parte del intercambio. Estas "pruebas de legitimidad" pueden abordarse, como ya se señaló en otro trabajo (Pizarro, 2017) a la luz de lo que Matta (2013) denomina formas de acreditación moral. Según este autor, "[...] El intercambio se encuentra enmarcado en un entramado de obligaciones sociales (morales) que, en caso de ser desatendidas por alguna de las partes involucradas, se convierten en un elemento de desacreditación moral de su persona [...] Cuando las personas concretan sus intercambios cotidianos no explicitan sus expectativas morales (confianza, buena fe, reciprocidad, etc.), aunque resulten constitutivas de la relación" (Matta, 2013: 15).

Otro concepto que nos ayuda a pensar esta relación es el de capital moral desarrollado por Wilkis (2015). Inspirado en la categoría de capital simbólico de Bourdieu, propone que las personas todo el tiempo están midiendo, comparando y evaluando sus virtudes morales, por lo cual ser reconocidos a través de esas virtudes implica poseer capital moral. $Y$ agrega que "hablar de capital moral es entender que se requiere ser reconocido por poseer ciertas virtudes para que se realice un préstamo o se participe en actividades que no están encuadradas en ninguna normativa legal" (2015: 563). En este sentido, los jóvenes destinatarios se inscriben en un escenario de disputas acerca de las valoraciones desplegadas en torno a ellos y sus acciones en un contexto específico. Esa dinámica conflictiva los orienta dentro de una disputa por el reconocimiento en la cual se los habilite moralmente a ser parte del intercambio y de esa forma ser reconocidos. En esta clave, Cardoso de Oliveira señala -recuperando los estudios sobre el intercambio realizados por Mauss (1979) y Malinowski (1972)- que "en varias circunstancias los actos de intercambio son ritualizados, donde la forma prescripta está cargada de significados y sugiere que el cumplimiento de la obligación moral involucrada en esos actos no se agota en la satisfacción de los intereses de las partes (en tener acceso al bien recibido o en instituir una obligación para con el socio), ni en la afirmación de un derecho, sino que requiere la demostración del reconocimiento del valor o mérito del receptor del don" (Cardoso de Oliveira, 2004: 27). Dicho esto, los destinatarios se embarcan en una disputa moral permanente, dentro de la cual deben rendir cuentas de su honor y dignidad a riesgo de ser juzgados por la opinión pública, el tribunal de la reputación, como señala Pitt-Rivers (1984). Esta disputa por el honor también encuentra dentro de la misma arena de luchas a los destinatarios enfrentados entre sí. Durante mi trabajo de campo fueron frecuentes las acusaciones al interior de este grupo, enlazadas dentro de tramas de significaciones más amplias y que se vinculan con lo expuesto anteriormente. La impugnación común, que incluso 
posicionaba a los jóvenes en un litigio moral con ellos mismos, tenía que ver con el manejo del estipendio mensual. En otra entrevista realizada durante 2014, una joven destinataria me comentaba:

Y... si me lo están dando para eso... Se publicita que es para eso, yo lo uso para eso. Trato de respetar. Después lo que hagan los demás allá ellos. Los beneficios que me dan si es específicamente para eso, yo los voy a respetar. A mí me enseñaron eso [...] El tema es si lo mal utilizas. Como yo lo uso para esto nada mas, a mi me alcanza perfecto (Comunicación personal, beneficiaria B, septiembre de 2014).

El fragmento señalado permite identificar la manera en que la joven se posiciona respecto al resto de sus adversarios morales, realzando valores como el respeto y la educación. Otra destinataria me decía:

\footnotetext{
Amigos... tengo una amiga que está cobrando que no debería cobrarlo y siempre tenemos la misma discusión, porque tiene... o sea, puede pagarse los estudios y yo se lo digo no tengo problema viste como soy. Eh... pero bueno, lo cobra y no lo usa responsablemente. $Y$ seguido tenemos la misma discusión porque ella me dice "ay no pasa nada agarra del PROGRESAR" y yo no, no me parece (Comunicación personal, beneficiaria C, septiembre de 2014).
}

Junto a este último fragmento encontramos la noción de responsabilidad a modo de imputación sobre el accionar de otra destinataria del programa, quien es juzgada en su calidad de beneficiaria y desacreditada moralmente bajo esta cualidad.

A mediados de 2016, en el medio de una serie de irregularidades en la gestión de Progresar, una joven comentaba en los pasillos de la facultad: "No es justo [...] Yo sé, porque sé, que hay gente que está recursando o que no meten una materia y sigue cobrando... ¿Cómo puede ser?". En su relato, la joven enfatizó sobre su condición de estudiante migrante proveniente de otra ciudad, haciendo hincapié en los gastos implicados en concepto de vivienda y estudios. En esta amalgama de sentidos, el valor de justicia se torna central en la impugnación de adversarios y la construcción del deber ser del destinatario: el estudiante que cursa y "mete materias", acreditando su mérito como receptor del don.

\section{Disputas y lealtades en la reorientación política}


En noviembre de 2015 el candidato de la alianza Cambiemos, Mauricio Macri, se consagró presidente electo de la República Argentina. En diciembre aconteció el cambio de gobierno y a partir de ese momento se previó una serie de modificaciones en la orientación de las políticas públicas. En lo que concierne al Progresar, 2016 constituyó un año impregnado por las irregularidades en la gestión y otorgamiento del programa que afectó a un amplio número de destinatarios, además de una reconfiguración de las dinámicas política y moral en los actores locales.

La modalidad de gestión descripta anteriormente que involucraba a la UNESO, la ANSES local y otras organizaciones políticas locales, se prolongó durante todo el ciclo académico de 2014. Esta actividad le permitió a la organización estudiantil tener un mayor acercamiento al conjunto de los estudiantes, ya que además de la instancia inicial del trámite, por lo menos dos veces al año también se encargaban de gestionar la certificación de regularidad de estudios de cada uno de los estudiantes inscriptos. En esos momentos, los militantes tenían la oportunidad de fortalecer los lazos con una considerable cantidad de estudiantes quienes eran naturales votantes para las elecciones gremiales estudiantiles, manera en la cual la implementación de esta política constituía nuevos lazos sociales y políticos (en algunos casos, estudiantes que eran acompañados por la agrupación durante su tramitación en el programa comenzaron a participar activamente en la organización).

A principios de 2015, se impulsó un acuerdo institucional entre la Federación Universitaria del Centro de la Provincia de Buenos Aires (FUCPBA) y la ANSES regional, con sede en Tandil. Esta decisión provocó algunos vaivenes políticos que encontró diversas posiciones al interior del frente político regional que en ese momento conducía a la federación y del cual la UNESO era parte. Algunos de los argumentos que se sostuvieron por parte de militantes de esta organización era que este nuevo acuerdo corrompía la eficacia con la cual se había gestionado el programa en la facultad el año anterior, ya que con esta nueva modalidad los tiempos de acreditación se extenderían por el envío de formularios hacia la unidad de atención tandilense y no había garantías de un control exhaustivo de las mismas. Además se esbozó alguna que otra sospecha, en medio de una reunión de $\mathrm{CE}$, de que el acuerdo era promovido por un militante estudiantil de Tandil quien a su vez trabajaba en ANSES, lo que significaba una manera de legitimar su puesto. A lo largo de ese ciclo académico, se registraron mayores irregularidades a diferencia del año anterior lo que generó un mayor descontento con esta nueva forma de gestión del programa en el sector estudiantil.

En 2016 otro actor político universitario irrumpe en la implementación de Progresar en la FACSO. En ese momento, con el cambio de gobierno a nivel local, provincial y nacional, todo acuerdo celebrado entre las organizaciones estudiantiles y el órgano estatal a cargo de la 
ejecución del programa quedó suspendido. Las oficinas locales de la ANSES se sometieron al reordenamiento político que, entre otras cosas, implicó un desplazamiento de las jefaturas locales por el cual trabajadores vinculados -según el relato oficialista del gobierno electo- a organizaciones kirchneristas fueron despedidos o relocalizados en otra área. Esto dificultó la concreción de relaciones institucionales que se tradujeran en acuerdos similares a los mencionados, situación acentuada por las claras diferencias políticas entre los distintos espacios estudiantiles y las nuevas jefaturas nombradas.

En este contexto, la Unión de Juventudes Socialistas (UJS-PO), brazo estudiantil del Partido Obrero, comenzó a denunciar incumplimientos en el pago del estipendio mensual del programa. A la par de estas manifestaciones, exigieron respuestas a la conducción del CE y en una sesión del Consejo Académico decidieron presentar un pedido a las autoridades de la FACSO y la UNICEN para que se tomaran medidas dirigidas a la solución de estas irregularidades. Mientras tanto, la conducción del CE (UNESO) promovió reuniones con la Secretaría de Bienestar de la FACSO para diseñar una modalidad de seguimiento que permitiera identificar aquellos casos en los cuales no se estaba garantizando el ingreso mensual estipulado. En ese sentido, desde la agrupación kirchnerista llevaron adelante una encuesta -online y en papel- a través de la cual se intentaba obtener un estado de situación que serviría de insumo a la Secretaría de Bienestar para promover acciones. Con el correr de los meses estos casos se fueron regularizando y la agenda política estudiantil viró hacia otros temas, especialmente el referido al boleto estudiantil gratuito. Sin embargo, se dio lugar a que diferentes valoraciones morales emergieran en un escenario de disputa política con el programa como articulador de esta contienda. En ese sentido, vale recuperar el comunicado que expresó la UNESO, como conducción del CE, cuando promovió la encuesta mencionada. En uno de sus pasajes se señalaba:

Para muchos esta política no era más que un par de monedas mensuales que se escapaban por la canaleta de la droga y el juego, un parche más a la ineficiencia del gobierno kirchnerista, un regalo a los vagos que ni estudian ni trabajan, un despilfarro más de la fiesta pasada. Tanto aquellos que pregonan un modelo de Estado favorable al mercado perjudicando gravemente a los sectores populares, como aquellos que nunca creyeron en el Estado como garante de derechos son cómplices tácitos y responsables de la situación actual que atraviesan políticas como Progresar. Éramos conscientes de que esta avalancha de revancha, injusticia, desigualdades y vaciamiento se avizoraba con la llegada de la derecha más recalcitrante al poder, en todo su esplendor.

Para nosotros, PROGRESAR siempre fue, es y será un derecho y no un mero oportunismo sensacional. Por tal, entendemos la inquietud de nuestros compañeros que tienen o han tenido inconvenientes, anteriormente 0 en el contexto actual de avanzada del 
neoliberalismo sobre las políticas de inclusión en todos sus ámbitos, sin distinción de afinidades ideológicas, como siempre lo hemos hecho (UNICEN, s.f.).

Se observa que en el posicionamiento expresado por la agrupación, se realiza una apropiación de frases y expresiones que se deslizaban en una ofensiva contra el Progresar, particularmente asociadas éstas con sectores políticos de la oposición. Oración siguiente, se lanza una acusación contra sectores que no eran devotos del programa atravesada por una representación del Estado como órgano garante de derechos, el cual puede ser objeto de creencia o no, o un elemento profanado al servicio del mercado en detrimento de las clases populares. Luego, se plantea de cierta manera que el grupo político ya había advertido acerca de las consecuencias que traería la llegada al poder de los sectores de derecha, de lo cual se desprende un intento de revalidar honores en la arena política. Finalmente, se da cierre con una sentencia contundente temporalizada sobre el pasado, el presente y el futuro, declarando que para un "nosotros", el Progresar se trata de un derecho. $Y$ en una clara línea dirigida a su contrapeso estudiantil agrupado en la izquierda trotskista, agregan que no es "un mero oportunismo sensacional", lo que se interpreta desde el juego retórico político de la UNESO, una condena a una indebida manipulación política [de un derecho] -lo que refuerza la desacreditación moral- avivada por el contexto de reorientación política, si bien se supone en contra de los preceptos de izquierda, también en clara oposición a la gestión estatal kirchnerista.

Este contexto de reorientación política además de tensionar relaciones políticas entre fracciones antagónicas -tal el caso señalado para el Centro de Estudiantes de la FACSO- trajo sobre la mesa el entramado de lealtades que se puso en juego en el nuevo escenario. Como se llegó a describir, la implementación del Progresar fortaleció los lazos políticos entre diferentes actores identificados dentro del kirchnerismo, situación que cooperó en la construcción de vínculos entre algunas/os estudiantes destinatarios del programa y organizaciones políticas locales como La Cámpora (LC), y, en algunos casos, los amplió. Esto es lo que sucedió con Joaquín, beneficiario del programa, estudiante de la FACSO y militante de la UNESO. Este joven, entre 2015 y 2016 realizó diferentes actividades en la órbita del Centro de Acceso a la Justicia (CAJ) a través de un programa que abarcaba a destinatarios de Progresar, especialmente dirigidas a la difusión e información acerca de las funciones y competencias de dicho espacio, como distintas problemáticas con las que podía tratar. Esa experiencia lo llevó a compartir diferentes actividades y encuentros con militantes de LC de una manera más sostenida en el tiempo y de forma regular (la UNESO y LC compartían jornadas y agenda ocasionalmente, principalmente durante periodos electorales). 
A principios de 2017 durante una entrevista me comentó sobre su nueva ruta burocrática, establecida a partir del cambio de gobierno y en un proceso de pocas definiciones acerca de la gestión del programa. Y en uno de sus pasajes, me dijo:

Sí. Y ahí se la di a $\mathrm{P}$, que es un compañero, entonces le digo "no me están aceptando la planilla, ¿te la puedo dar a vos?", "Si, dámela". Y me cargó él enseguida como para que yo cobre ese retroactivo porque si no, no iba a cobrar. Y los empleados decían que no, que "la facultad lo carga". Y la facultad decía que ANSES lo cargaba. Después la facultad dijo que sí, que lo cargaban ellos pero ahora no sé cómo estará. Era la planilla de escolaridad. Si. P me atendió varias veces porque primero me atendió para, eh, cómo es, la declaración jurada que también me la hizo, directamente me dijeron que pase a hablar con $P$. Yo estaba en el CAJ en ese momento. Y del CAJ también hacíamos todos los Progresar y eso, entonces dijeron "bueno, vos pasa directamente con P" cosa de no hacer toda la fila y eso. Entonces Pablo me hizo directamente toda... Que él me parece estaba ahí... (Comunicación personal, Joaquín, mayo de 2017).

Aquí resulta relevante pensar la cuestión de la lealtad y las retribuciones enmarcadas en una relación de reciprocidad. Joaquín mantenía un vínculo, generado a partir de relaciones previas en el contexto de su militancia, con uno de los trabajadores de ANSES. Este último ocupó la jefatura de la dependencia local de ANSES y era referente de una organización política kirchnerista vinculada fuertemente a la implementación del Progresar. Una vez sucedido el cambio de gestión, es apartado de la jefatura y derivado a otra área. Es interesante, en ese nuevo contexto, cómo los vínculos enlazados desde una retórica militante se articulan con procesos de demanda. Esto, más allá de evaluaciones políticas, permite pensar múltiples dimensiones socioculturales que intervienen y dan forma a relaciones más amplias de reciprocidad, en la cual convergen elementos como la retribución, la lealtad -identificada en este caso con la narrativa del "compañero"- y el reconocimiento. En este sentido, desde una retórica política asociada al kirchnerismo y enraizada desde sus bases con el peronismo, Joaquín espera, por parte del trabajador de ANSES, una acción que se considere coherente con los valores asociados a los lazos entre "compañeros". En un contexto político adverso a los intereses que organizaciones como las que se mencionan aquí proponen, las relaciones de reciprocidad parecen reforzarse a través de los valores que se ponen en juego, como la lealtad. Balbi (2005) examina en un artículo el momento temprano del proceso a través del cual el concepto de lealtad llegó a tornarse en un componente central de las formas en que los peronistas conciben y desarrollan sus actividades políticas. Allí señala que la lealtad, expresa algo más que un término característico de una retórica empleada por los peronistas para 
posicionarse políticamente en sus relaciones, "pudiendo ser legítimamente entendida como un valor moral específicamente peronista que es el producto histórico de ciertos procesos sociales pasados y presentes, en torno del cual se agrupan rituales, comportamientos ritualizados y narraciones estandarizadas, y que constituye un factor eficiente en la praxis de los peronistas, operando simultanea e indisociablemente como parámetro y como medio de sus conductas" (Balbi, 2005: 2). Más adelante, el autor sintetiza los sentidos asociados inicialmente al concepto peronista de lealtad, mencionando entre ellos: a. la lealtad es una virtud de carácter moral; b. constituye una cualidad inherente a las personas, que simplemente está o no presente en ellas; c. es recíproca, constituyendo la base de las relaciones entre compañeros (Ibídem: 5). Estas ideas aparecen como esclarecedoras del tipo de relación que mantiene unidos a Joaquín y el ahora jefe desplazado del organismo estatal, las cuales contribuyen para la comprensión de sus ideas y acciones desplegadas que parecen asentarse sobre una fuente de confianza entre compañeros.

\section{Palabras finales}

A lo largo del trabajo se han explorado dimensiones políticas y morales que intervienen en la implementación de Progresar y que se expresan a través de una serie de tramas de significados que enlazan valores, sensibilidades legales, relaciones de reciprocidad, actores y prácticas. El recorrido por algunas de las relaciones políticas generadas en el marco de la implementación del programa y los aspectos morales que emergen, tanto al interior de un grupo político como alrededor de los y las destinatarias, dejó entrever que la experiencia de una política social pone en juego múltiples sentidos y relaciones construidas que se despliegan a la luz de su implementación. De esta manera, podemos señalar que la heterogeneidad significacional acerca de Progresar constituye un aspecto central en su interpretación, dando lugar a diversos y singulares modos de acción que se apoyan en variados esquemas de significación, poniendo en tela de juicio normativas oficiales y moralidades nativas, y activando diferentes aspectos que constituyen el aspecto multivocal de este tipo de política. Como señala Hornes (2012) estas aproximaciones permiten "sumar elementos para comprender como las políticas de Estado y gobierno son experimentadas e interpretadas por las poblaciones locales, considerando las tensiones o luchas políticas, culturales y simbólicas existentes entre la diversidad de actores e instituciones involucradas" (2012: 110). 
(1) Lo expuesto en este trabajo se desprende de la ponencia PROGRESAR: ¿Un nuevo derecho? Abordaje etnográfico sobre las implicancias de una transferencia condicionada de ingresos en un contexto de reorientación de las políticas públicas, presentada en las XI Jornadas de Jóvenes Investigadores en Ciencias Antropológicas que se desarrollaron en el Instituto Nacional de Antropología y Pensamiento Latinoamericano, Buenos Aires, del 6 al 10 de agosto de 2018.

(2) Decreto Nro. 84/2014 del Poder Ejecutivo Nacional. Recuperado de https://www.boletinoficial.gob.ar/\#!DetalleNormaBusquedaAvanzada/101157/20140127

(3) Para ver las diferentes modificaciones: http://servicios.infoleg.gob.ar/infoleglnternet/anexos/225000229999/225728/texact.htm

(4) Discurso de Cristina Fernández de Kirchner, 22 de enero de 2014. Recuperado de https://www.cfkargentina.com/cristina-presento-el-plan-progresar-programa-de-respaldo-a-estudiantes-argentinos/

(5) En sentido histórico, esta categoría se vincula directamente con el modelo neoliberal y fue durante su época de hegemonía que se gestó y se extendió a modo de caracterización de jóvenes "que no estudian ni trabajan", destacándose la falta de empleo, la deserción escolar y la baja de calidad educativa como detonantes (Mazzola, 2014). El origen etimológico se remonta al acrónimo ingles NEET, not in employment, educationor training (ni trabaja, ni estudia ni recibe formación), resultando de uso atractivo para los medios de comunicación.

(6) Para una mayor referencia sobre los estudios enfocados en los significados sociales del dinero en las políticas sociales, resultan pertinentes los aportes de Hornes $(2012,2013,2014)$, quien considera que "el dinero condicionado que se transfiere desde los programas sociales circula investido de valores personales, morales y familiares, de manera tal que en su tránsito sus significados se convierten o subvierten, se generan asimilaciones directas o disrupciones" (Hornes, 2012: 108-109).

\section{Bibliografía}

Pizarro, M. (2017). Progresar: Un abordaje etnográfico sobre las moralidades asociadas a un programa de Transferencia Condicionada de Ingresos. Revista Kula. Antropólogos del Atlántico Sur, 15-16, pp. 28-39.

Balbi, F. (2005). '...esa avalancha de homenajes': campo de poder, lealtad y concepciones de política en el primer peronismo. Anuario de Estudios en Antropología Social, 2004. Centro de Antropología Social-Instituto de Desarrollo Económico y Social (CAS-IDES), Buenos Aires, pp. 103-118. Recuperado de http://www.historiapolitica.com/datos/biblioteca/balbi.pdf

Cardoso de Oliveira, L. R. (2004). Honor, dignidad y reciprocidad. Cuadernos de Antropología Social, 20, pp. 25-39.

Decreto 84/2014. Boletín Oficial de la República Argentina, Buenos Aires, 23 de enero de 2014. Recuperado de https://bit.ly/2UHHAEt 
Geertz, C. (1994). Conocimiento local: Hecho y ley en la perspectiva comparativa. En Conocimiento local. Ensayos sobre la interpretación de las culturas (pp.195-287). Barcelona: Paidós.

Hornes, M. (2012). Los programas de transferencias monetarias condicionadas. Una aproximación desde la socioantropología económica. Revista Debate Público. Reflexión de Trabajo Social, 5, pp. 103-112.

Hornes, M. (2013). Transferencias condicionadas y sentidos plurales: el dinero estatal en la economía de los hogares argentinos. Revista Antípoda. Recuperado de https://antipoda.uniandes.edu.co/view.php/281/index.php?id=281

Hornes, M. (2014). Controversias públicas en los significados del dinero. IX Jornadas de Estudios Sociales de la Economía. La dimensión social de los procesos y objetos económicos. Universidad Nacional de San Martín, Instituto de Altos Estudios Sociales, Centro de Estudios Sociales de la Economía, Buenos Aires, Argentina.

Matta, J. P. (2013). Intercambios, moralidades y conflictos. Intersecciones en Antropología, 14, UNICEN, pp. 171-183.

Mauss, M. (1979). Ensayo sobre los dones. Motivo y forma del cambio en las sociedades primitivas. En Sociología y Antropología. Madrid: Editorial Tecnos.

Mazzola, R. (2014). PROGRESAR. Juventudes, bienes públicos y justicia distributiva. Revista Estado y Políticas Públicas, 2, pp. 91-113.

Pitt-Rivers, J. (1979). La antropología del honor. En Antropología del honor o política de los sexos. Barcelona: Editorial Crítica.

Universidad Nacional del Centro (UNICEN). (s.f.). Biografía [página de Facebook]. Recuperado 30 de junio de 2016 de https://www.facebook.com/cesociales.olavarria/

Wilkis, A. (2013). Las sospechas del dinero. Moral y economía en la vida popular. Buenos Aires: Paidós.

Wilkis, A. (2015). Sociología moral del dinero en el mundo popular. Estudios Sociológicos XXXIII(99), pp. 553-578. 